\title{
ESTs and EST-linked polymorphisms for genetic mapping and phylogenetic reconstruction in the guppy, Poecilia reticulata
} Christine Dreyer*, Margarete Hoffmann, Christa Lanz, Eva-Maria Willing, Markus Riester, Norman Warthmann, Andrea Sprecher, Namita Tripathi, Stefan R Henz and Detlef Weigel

Address: Department of Molecular Biology, Max Planck Institute for Developmental Biology, Tübingen, D72076, Germany

Email: Christine Dreyer* - christine.dreyer@tuebingen.mpg.de; Margarete Hoffmann - margarete.hoffmann@tuebingen.mpg.de; Christa Lanz - christa.lanz@tuebingen.mpg.de; Eva-Maria Willing - eva.willing@tuebingen.mpg.de; Markus Riester - riester@bioinf.unileipzig.de; Norman Warthmann - norman@warthmann.com; Andrea Sprecher - andrea.sprecher@tuebingen.mpg.de; Namita Tripathi - namita.tripathi@tuebingen.mpg.de; Stefan R Henz - stefan.henz@tuebingen.mpg.de; Detlef Weigel - weigel@weigelworld.org * Corresponding author

Published: 8 August 2007

BMC Genomics 2007, 8:269 doi:10.1/86/147|-2164-8-269
Received: 16 February 2007

Accepted: 8 August 2007

This article is available from: http://www.biomedcentral.com/I47I-2/64/8/269

(C) 2007 Dreyer et al; licensee BioMed Central Ltd.

This is an Open Access article distributed under the terms of the Creative Commons Attribution License (http://creativecommons.org/licenses/by/2.0), which permits unrestricted use, distribution, and reproduction in any medium, provided the original work is properly cited.

\begin{abstract}
Background: The guppy, Poecilia reticulata, is a well-known model organism for studying inheritance and variation of male ornamental traits as well as adaptation to different river habitats. However, genomic resources for studying this important model were not previously widely available.

Results: With the aim of generating molecular markers for genetic mapping of the guppy, cDNA libraries were constructed from embryos and different adult organs to generate expressed sequence tags (ESTs). About 18,000 ESTs were annotated according to BLASTN and BLASTX results and the sequence information from the 3' UTRs was exploited to generate PCR primers for re-sequencing of genomic DNA from different wild type strains. By comparison of EST-linked genomic sequences from at least four different ecotypes, about I,700 polymorphisms were identified, representing about 400 distinct genes. Two interconnected MySQL databases were built to organize the ESTs and markers, respectively. A robust phylogeny of the guppy was reconstructed, based on 10 different nuclear genes.
\end{abstract}

Conclusion: Our EST and marker databases provide useful tools for genetic mapping and phylogenetic studies of the guppy.

\section{Background}

The Trinidadian guppy, Poecilia reticulata Peters, is well known for the highly polymorphic male color patterns, which have been the subject of genetic analysis for almost a century [1]. The vast literature on the ecology and evolution of the guppy and the extensive phenotypic variation in wild populations make the guppy a particularly attrac- tive choice for understanding the molecular basis of adaptation to varying natural conditions. Despite the wealth of field studies, molecular genetic information about the guppy is still scarce. Therefore, a genetic map would be a first step towards identifying quantitative adaptive traits of the guppy, including male ornamentation and predator-driven adaptations found in different river habitats in 
Trinidad, underlying heritable differences in life history traits $[2,3]$.

The genome size of the guppy is estimated to be around $740 \mathrm{Mbp}$, with a diploid set of 46 chromosomes, including genetically defined $\mathrm{X}$ and $\mathrm{Y}$ sex chromosomes [4]. A first map of the sex chromosomes, based on classical genetic analysis of male colour patterns, has been sketched out by Winge and co-workers [5]. More recently, Phang and co-workers used ornamental guppies from Singapore to generate a genetic map based on 300 RAPD markers, and a cross between two laboratory strains of different body shape and colour was mapped using a combination of 186 AFLP and microsatellite markers [6-8]. Conservation of microsatellites between closely related species and synteny with respect to 61 microsatellite markers were suggested by an intergeneric cross between Xiphophorus maculatus [9] and $P$. reticulata [10]. In all of these studies, the number of linkage groups fell short of the chromosome number, indicating that a higher marker density is required for complete coverage of the genetic map. Unfortunately, RAPD and AFLP markers cannot be easily reused for studying crosses between outbred strains of wild guppies.

We have identified hundreds of expressed sequence tag (EST)-linked single nucleotide polymorphism (SNP) markers, suitable for genetic mapping of wild guppies. The fact that these markers are linked to expressed genes will help to exploit syntenic information from fully sequenced genomes of other fish species [11]. This will in turn also facilitate future identification of candidate genes when mapping qualitative morphological as well as quantitative life history traits of the guppy.

\section{Results and discussion}

A P. reticulata EST database

Several guppy cDNA libraries were constructed using SMART technology, as detailed in Materials and Methods. As sources of mRNA we used whole embryos, newborn fish, adult liver, testis, brain, retina, and skin, in order to obtain a broad spectrum of different expressed sequences. Several feral and laboratory strains were used, including the Quare6 strain from East Trinidad and the Tranquille strain from West Trinidad [12]. This allows for direct sequence comparison of abundant transcripts between different strains. Between 100 and 5,700 clones were picked at random from each library, depending on its complexity. The inserts were first sequenced from the $5^{\prime}$ end and sequences were compared to EMBL vertebrate databases (see Methods) using NCBI BLASTN and BLASTX algorithm [13] to assign a possible function. BLAST results were parsed and automatically entered into a MySQL EST database [14]. Sequences lacking sufficiently good support by BLAST hits with an e-value higher than $10^{-5}$ were not entered into the database, but were set aside for periodically repeated subsequent BLAST searches.

Our EST database http://guppy.weigelworld.org currently comprises about 18,000 entries, which represent about 5,300 different gene products. The Quare and Tranquille strains are represented by about $40 \%$ of the entries each, with the remaining $20 \%$ derived from other strains, including the laboratory strains Blue and Istanbul wild [15] (Table 1). About 16,200 ESTs with a minimum of 200 bp sequence available have been deposited to Genbank. The accession numbers are included in Table 1.

The results of the BLASTX searches were parsed for annotation according to GO criteria [16], describing molecular function or biological processes, provided that the E-value of the best hit was lower than $10^{-5}$ (Fig. 1). Most of the proteins encoded by non-redundant annotated guppy ESTs have binding $(17 \%)$ or catalytic $(13 \%)$ activity or are structural proteins $(13 \%)$. This distribution resembles that described for the Fundulus heteroclitus EST database [17], although the guppy database contains relatively more ESTs derived from retina, testis, and muscle. Among enzymes and structural proteins, muscle proteins are the most abundant, because somite tissue prevails in advanced embryos, the predominant source of our EST libraries (Table 1). Sequences without significant best BLAST hits or with hits to genes that lacked informative annotation, e.g. from genomic surveys or non-annotated EST products, are listed as unknown in Table 2. About $25 \%$ of the guppy cDNAs in our database is annotated as unknown.

The EST database can be searched by clone name, by accession number of the best BLAST search hit, and by possible biological function of the deduced protein product of each EST. Furthermore, the BLAST hits are saved in a table, in which a full text search for annotations as well as accession numbers can be performed. A subset of EST clones was also sequenced from the 3' end, and the longest ORF was extracted from the assembly with its $5^{\prime}$ sequence. Information on the coding regions was obtained by database searches using BLASTX. Contigs representing multiple hits of the same gene product were aligned in order to analyse these for polymorphisms.

We provide a download function for the extraction of the 5 ' and 3 ' end cDNA sequences, as well as assemblies in the FASTA format [18]. It is also possible to perform BLAST searches against all ESTs.

\section{Development of single nucleotide polymorphism (SNP) markers in guppies}

For identification of polymorphisms, we used ESTs to design PCR primers for amplification from genomic DNA 
Table I: Origin of guppy ESTs

\begin{tabular}{|c|c|c|c|}
\hline Source of cDNA & Clones* & Strain & Clones \\
\hline Tranquille Embryo & 4885 & & \\
\hline Tranquille Liver & 2007 & Tranquille & 6892 \\
\hline Quare Embryo & 2731 & & \\
\hline Quare Testis & 1536 & & \\
\hline Quare Head & 143 & & \\
\hline Quare Liver & 554 & Quare & 4964 \\
\hline Oropuche Skin & 1483 & & \\
\hline Oropuche Retina & 837 & & \\
\hline Oropuche Embryo & 84 & Oropuche & 2404 \\
\hline Blue Testis & 2560 & & \\
\hline Blue Brain & 951 & Blue & 3511 \\
\hline Istanbul wild Skin & 348 & Istanbul wild & 348 \\
\hline Total & 18119 & & 18119 \\
\hline
\end{tabular}

*Clones for which sequence information was less than 200 nucleotides have not yet been submitted to Genbank. The accession numbers of the submitted clones are: ES37095I-ES387I46

of different strains. We primarily amplified 3' UTR sequences, because they are less conserved than coding sequences and not interrupted by introns. The 3' UTRs are typically shorter than in mammals, as has been reported for other lower vertebrates [19]. This somewhat reduces the usefulness of 3' UTRs for identification of SNPs by resequencing of genomic DNA from different strains. Several EST libraries were constructed (Table 1) and some consisted of size-selected sub fractions (data not shown). In the different libraries, between 10 and $30 \%$ of the cDNA sequences had 3' UTRs longer than 400 bp and those were given priority. The $3^{\prime}$ end of the coding sequence was included where required to produce fragments about 400 to 500 bp in length. In many instances, PCR amplification and sequencing revealed that the 3 ' ends of coding regions contained short (<100 bp) introns. A comparison of ESTs from different strains reveals that, as expected, coding sequences are less polymorphic than the 3 ' UTRs.

Some primers that were designed to flank an intron were also used, yet their efficient design required prediction of the most likely exon-intron boundaries by alignment of the ESTs to genomic sequences from other fish species, and the length of the resulting PCR products was unpredictable. Aside from SNPs, 3' UTRs and introns also contained short insertions and deletions (indels) at lower frequency (about 20\% of all polymorphisms). Of these indels, about $60 \%$ were found as parts of either short tandem repeat polymorphisms or of homopolymer stretches (data not shown).

Table 2: Composition of guppy EST database by annotation

\begin{tabular}{|c|c|c|c|c|c|}
\hline GO criterion & Different & Total & Most frequent & Number & $\%$ In this category \\
\hline Binding & 1175 & 3229 & Apolipoprotein A-IV-4 & 256 & 7.9 \\
\hline Catalytic activity & 1098 & 2815 & Muscle CKMI & 271 & 9.2 \\
\hline Structure & 357 & 2396 & MLC-2 & 278 & 11.6 \\
\hline Ribosomal protein & 135 & 783 & L3 & 88 & 11.2 \\
\hline Signal transduction & 271 & 1235 & DEAD box DDX5 & 478 & 38.7 \\
\hline Transcription factor & 236 & 425 & $\begin{array}{l}\text { Cold shock domain } \\
\text { fruYPI }\end{array}$ & 43 & II.I \\
\hline Translation factor & 71 & 314 & EFla & 149 & 47.5 \\
\hline Receptors & 89 & 152 & $\begin{array}{l}\text { Receptor for activated } \\
\text { prot K }\end{array}$ & 15 & 9.9 \\
\hline Immune system & 43 & 69 & CD6 precursor & 6 & 0.9 \\
\hline Cell cycle & 29 & 84 & Cyclin GI & 18 & 21.4 \\
\hline Proteolysis & 9 & 12 & 20 s proteasome & 5 & 41.7 \\
\hline Others & 1108 & 1809 & Vitellogenin & 51 & 28.2 \\
\hline Unknown & 670 & 4346 & $\begin{array}{l}\text { No significant } \\
\text { homology }\end{array}$ & 3000 & 69.0 \\
\hline SUM & 5291 & 17669 & & & \\
\hline
\end{tabular}




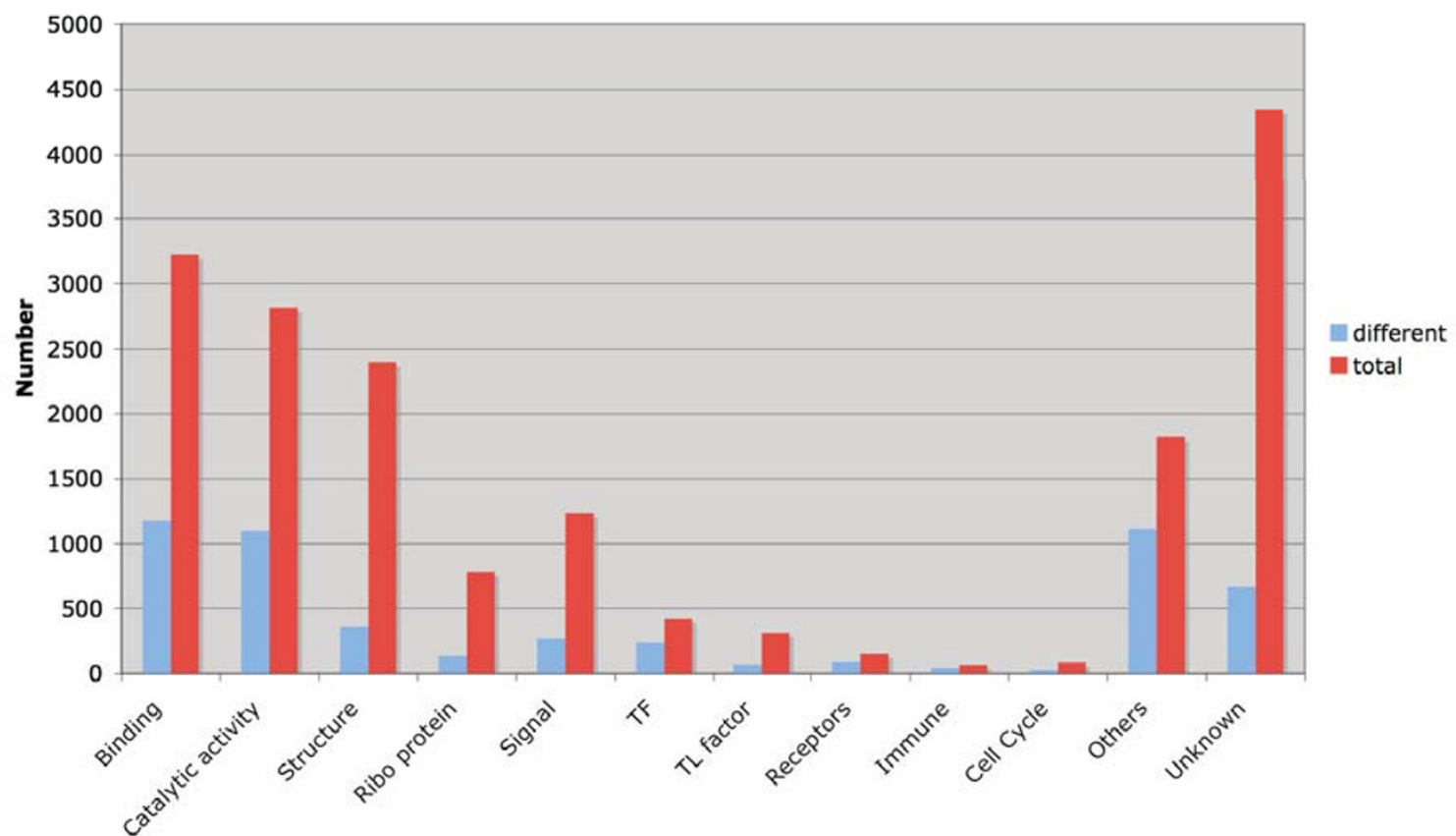

Annotation

\section{Figure I}

Classification of deduced gene products represented in the guppy EST library. Annotations of the best hits found by BLASTX searches against public databases were parsed and classified according to molecular function or biological process. The group of others includes about 3000 ESTs with hits whose E-value was not better than $10^{-5}$ Red: number of different ESTs, blue: number of total ESTs.

A second MySQL database was established for the management of the strain-specific markers and was linked to the EST database. From the marker database information can be retrieved on the reference clone, the primer pairs used, type (SNP, indel), and position of polymorphisms between genomic sequences of the different guppy strains. The marker database can also accommodate information on available assays for these polymorphisms. So far, these are mainly MALDI TOF assays developed for high throughput detection of SNP markers [20]. All multiple alignments of genomic and cDNA sequences that had been generated for polymorphism detection [21] were loaded into the multiple SNP query tool (MSQT), a database used for SNP assay development, especially for design of strain-specific assays (Warthmann, Fitz and Weigel, submitted).

From 400 unique ESTs that were successfully resequenced in 16 strains of guppy, we could identify 1,700 EST linked polymorphic loci. About $75 \%$ of the polymorphisms were identified by comparison of only four popu- lations, originally collected in the Quare (East Trinidad), Tranquille and Upper Aripo rivers (West Trinidad), and in Central Cumaná (Venezuela). The geographically most distant among these are the Quare and the Cumaná guppies and we found these to be most genetically divergent. As shown in Table 3, the evaluation of 400 polymorphic ESTs using the MSQT, allowed for the selection of 235 assays for markers that are each linked to a different gene product and that distinguish between Quare and Cumaná populations. A similar or slightly smaller number of assays were predicted to distinguish other pairs of ecotypes (Table 3). For analysis of genetic crosses between different feral guppy strains, these EST-linked SNP markers can be supplemented by about 50 microsatellite markers previously described in guppies $[10,23,24]$.

BLAST searches with the guppy ESTs selected for marker development were performed against the Tetraodon nigroviridis genome. The number of hits for each chromosome was approximately proportionate to the length of each $T$. nigroviridis chromosome and indicated that at least two 
Table 3: Polymorphisms in nuclear genes that distinguish strains

\begin{tabular}{|c|c|c|c|c|}
\hline Strain & Quare & Cumaná [24] & APUFI & Tranquille \\
\hline Quare & & 597 & 614 & 546 \\
\hline Cumaná [24] & 235 & & 499 & 438 \\
\hline APUFI & 236 & 205 & & 469 \\
\hline Tranquille & 202 & 164 & 182 & \\
\hline
\end{tabular}

Numbers above the diagonal refer to the total number of polymorphisms in the dataset, numbers in bold refer to polymorphisms representing one distinct EST each.

markers corresponding to each Tetraodon chromosome had been identified. Another $38 \%$ of these sequences aligned to the $40 \%$ of the Tetraodon sequences that were not yet assigned to one of its 21 chromosomes (Fig. 2, and data not shown). Similarly, guppy ESTs were aligned to genomic sequences of zebrafish (Danio rerio), fugu (Takifugu rubripes) and medaka (Oryzias latipes), to facilitate prediction of potential coding sequences in regions of interest for mapping, genomic walking, and for prediction of exon-intron boundaries (data not shown). Since a certain degree of synteny between different fish species has been previously described $[10,24]$, a higher marker density in regions of interest for genetic mapping may be achieved by ortholog cloning based on synteny predictions on genes in the guppy. However, even between close relatives, this approach will not work perfectly, given the

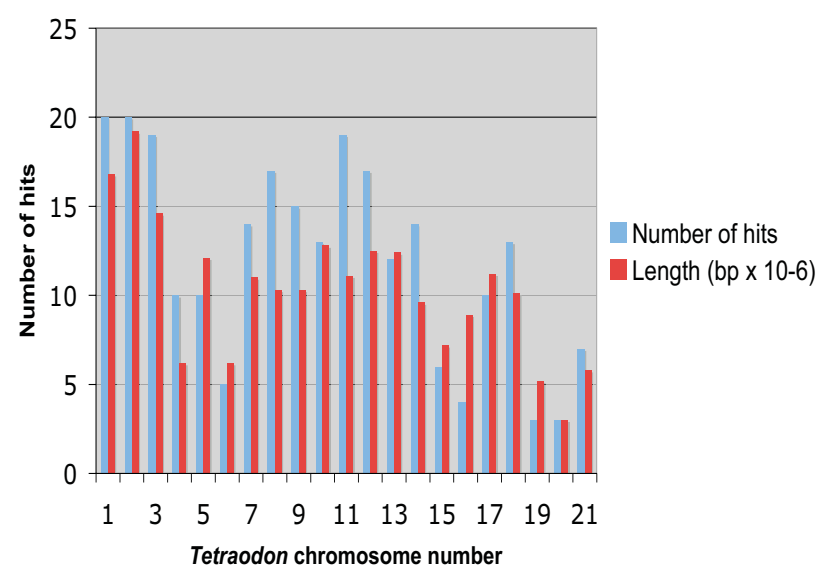

\section{Figure 2}

Mapping of guppy ESTs to Tetraodon nigroviridis chromosomes. ESTs for which polymorphic markers were identified by resequencing of genomic DNA were mapped to chromosomes of $T$. nigroviridis, according to their best hits. Relative length of each $T$. nigroviridis chromosome (blue) and number of guppy markers (red) are plotted. Of 387 significant hits, 136 (38\%) were assigned to the fraction of the $T$. niroviridis genomic sequences not yet annotated by chromosome number. fact that chromosome numbers are variable and chromosomal rearrangements occur frequently.

\section{Molecular phylogeny of the guppy}

Previous molecular phylogenetic studies on guppies were primarily based on mitochondrial sequences [25]. The molecular resources we developed enable studies on molecular evolution of nuclear genes, e.g. the identification of genes that have rapidly diversified and are potentially under positive selection, as exemplified by a study comparing genes encoding the long wave length sensitive opsins to other opsins [26].

Additional applications include studies on molecular phylogeny of the guppy. Coding sequences of orthologous expressed nuclear genes from nine different fish species, including the guppy, were identified by reciprocal BLAST. For phylogenetic analysis, these sequences were concatenated and a BIONJ tree was reconstructed [27], using SplitsTree4 software, version 4.6 [28] [see Additional file 1]. The selected genes include highly conserved ribosomal proteins as well as metabolic enzymes and transcription factors [see Additional file 2]. The number of teleost species in this analysis was limited by available sequence data from so-called non-model species, since the intersection of orthologous genes got smaller the more non-model species were included.

The resulting topology was essentially the same when only four coding sequences were concatenated. By convergence tests using increasing numbers of nuclear genes we showed that the pairwise distance statistics and the bootstrap values further improved upon addition of more sequences. This showed that a stable tree topology requires seven or more genes (data not shown). Furthermore, the topology of the phylogenetic tree was the same when maximum likelihood or maximum parsimony estimation was used instead of BIONJ (data not shown). This is in agreement with previously published comparisons of reconstruction methods, showing that BIONJ is not inferior to maximum likelihood [29]. This tree confirms previous phylogenetic studies on Poeciliid fishes, based on morphological criteria [30,31] and on genomic sequences $[25,32,33]$. In the future, intraspecific polymorphisms 
found in nuclear genes of feral guppy populations of different origins will be compared to previous phylogenies of different guppy strains [34] (Willing et al. in preparation). This will enable investigation of population structure and mapping of quantitative adaptive traits.

\section{Conclusion}

We established a non-normalized EST library of the guppy from embryos and six different adult tissues, containing 18,000 entries with three-fold redundancy on average. We show that re-sequencing of 3' UTRs from genomic DNA of different guppy strains is a powerful strategy to identify polymorphisms existing between feral guppies of geographically different origins.

Sequence information of 10 nuclear coding genes is sufficient to reconstruct a robust teleost phylogeny including the guppy Poecilia reticulata.

\section{Methods}

\section{Guppy Strains}

We used the laboratory strains Istanbul wild and Blue [15] as well as offspring from wild-caught guppies that had been kept in the laboratory for multiple generations. The wild guppies were from the following locations: Lower Oropuche and Quare Rivers strains (Oropuche Drainage, Trinidad); Tranquille and APUFI strains (Caroni Drainage, Trinidad); Cumaná guppies (central Cumuná, Ve; EnCCFR) [35], and PV6 (Rio San Miquel, Estado Sucre, $\mathrm{Ve})$.

\section{RNA isolation}

Whole late-eyed and very late-eyed embryos were isolated from euthanised pregnant females. Embryos as well as newborn fish and tissues from adult guppies were frozen in liquid nitrogen. Frozen embryos, newborn fish, or small pieces of tissue (Table 1) were homogenized for 90 seconds using a rotor-stator homogenizer (Polytron Pt 1200 , Kinematica) at full speed and total RNA was isolated using an RNAeasy Miniprep or Midiprep kit (Qiagen). RNA from male skin was prepared using Trizol (Invitrogen). Starting with total RNA extracted from whole embryos of the Quare6 and Tranquille strains, newborn fish (Tranquille), adult liver (Tranquille), testis (Blue), or skin (Oropuche2), polyA+ RNA was enriched using Quiagen Oligotex on a spin column.

\section{cDNA Libraries}

Total RNA was reverse transcribed and cloned into a pDNRlib vector utilizing a creatorSMART ${ }^{\mathrm{TM}} \mathrm{CDNA}$ construction kit (Clonetech). The cDNA was amplified by 18 cycles of long distance PCR using BD Advantage $2 \mathrm{PCR}^{\mathrm{TM}}$ enzyme mixture, following the manufacturer's protocols.
Alternatively, cDNA was transcribed from polyA+ RNA using the manufacturer's protocol for primer extension, which included only 6 to 10 cycles of PCR. Size fractionation of the double stranded cDNA after digestion with SfiI was performed on a $1.2 \%$ low melting agarose gel stained for 2 min with $0.1 \%$ methylene blue. After ligation, the products were dialysed against $\mathrm{H}_{2} \mathrm{O}$ for 20 minutes on a $0.025 \mu \mathrm{m}$ Millipore filter before transformation into electro competent ElectroTen-Blue cells (Stratagene). Clones were picked at random and plasmid DNA was isolated with a BioRobot 8000 using MagAttract 96 minipreps (Qiagen). cDNAs were sequenced from both ends using the pDNRlib-specific vector primers pDNRfw: AGTCAGTGAGCGAGGAAGC or pDNRrev: CCAAACGAATGGTCTAGAAAG on an Applied Biosystems 3730xl DNA Analyzer. The resulting sequence trace files in $\mathrm{ABI}$ format were processed with pregap4 (Staden package), using the phred base calling algorithm [36]. Vector sequence and low quality sequence was trimmed [21].

The cDNA was preliminarily annotated based on the best hit resulting from BLAST (version 2.5.15) or BLASTX against the actual version of vertebrate databases available in the GCG Wisconsin Package (em_vrt, embl_new, tags_new, nr) [22].

\section{EST database}

A Perl script ran nightly NCBI BLASTN and BLASTX jobs for new ESTs as well as for ESTs with BLAST results older than a given time period. The BLAST information, including clone name, strain and tissue of origin, were stored in the MySQL EST database (MySQL version 5.027-max; binaries and documentation can be downloaded from [14]. A PHP (version 5.1.2) web interface allows userfriendly access to this information and download of all sequences in FASTA format.

Additional links allow direct access to alignments of guppy ESTs with genomic sequences of Oryzias latipes, Tetraodon nigroviridis, and Takifugu rubripes [37]16,200 ESTs with a minimum length of 200 bp available sequence have been submitted to Genbank (see Table 1 for accession numbers).

The internal features of the database include a PHP web interface for administrative tasks like uploading new ESTs, updating of annotation, adding and changing position of introns (predicted and found in genomic sequences) as well as entering links to markers listed in the MySQL marker database that also has a PHP web interface.

\section{Analysis of genomic sequences}

Gene-specific PCR primers (18 to 23 mers, $\mathrm{T}_{\mathrm{m}} 59^{\circ}$ to $62^{\circ} \mathrm{C}$ ) were designed from $P$. reticulata cDNAs using the Primer3 program (release 1.0) [38]. Genomic DNA was 
extracted using a DNeasy Tissue kit (Qiagen), and was amplified by PCR using a mixture of Taq polymerase and Pfu (Fermentas; 1000:1 dilution) and following the protocol: $94^{\circ} \mathrm{C}$ for $5 \mathrm{~min} ; 5$ cycles of $94^{\circ} \mathrm{C} ; 30 \mathrm{sec} ; 60^{\circ} \mathrm{C}, 30$ sec; $68^{\circ} \mathrm{C}$, $90 \mathrm{sec}$, followed by 31 cycles of $94^{\circ} \mathrm{C}, 30 \mathrm{sec}$; touchdown to annealing temperature from 68 to $56^{\circ} \mathrm{C}$, $30 \mathrm{sec} ; 68^{\circ} \mathrm{C}, 90 \mathrm{sec}$, and a final elongation step of $68^{\circ} \mathrm{C}$ for $6 \mathrm{~min}$. PCR products were purified using Bioline Quick Clean and sequenced, using the same forward primers as in the original PCR. Alternatively, M13forward and reverse tags had been added to the gene-specific primers; the PCR protocol was $94^{\circ} \mathrm{C}$ for 5 min, 35 cycles of $94^{\circ} \mathrm{C}, 30 \mathrm{sec} ; 59^{\circ} \mathrm{C}, 30 \mathrm{sec} ; 68^{\circ} \mathrm{C}, 90 \mathrm{sec} ; 68^{\circ} \mathrm{C}$ for $6 \mathrm{~min}$. Sequencing was performed using M13 forward (5'TGTAAAACGACGGCCAGT-3') or reverse (5'-CAGGAAACAGCTATGACC-3') primers.

\section{Phylogenetic analysis}

Genes were included in the dataset if they met the following criteria: (1) orthologous sequences in each of ten species, and (2) alignable over most of the coding region. Genes were searched by reverse BLAST between the guppy and each of the nine other species, and considered to be homologues if they had significant TBLASTX scores (Evalue $<10^{-50}$ ) and reliable sequence identity values ( $\mathrm{min}$ imum $70 \%$ identity with $D$. rerio and more than $95 \%$ identity with $X$. maculatus). The open reading frame of each gene was manually examined after translating the nucleotide sequences with the getorf module from the EMBOSS package [39], version 3.0 [40].

The coding regions were aligned in a codon-based manner, by translating the nucleotide sequences into peptide sequences with transed included in the EMBOSS package and than aligning them with MUSCLE, version 3.6 [41]. Afterwards the nucleotide alignment was done based on the peptide alignment using the tranalign module included in the EMBOSS package [39]. Flanking gap regions were deleted.

For tree estimation, the ten nucleotide alignments for each species were concatenated to obtain a single alignment. The tree shown in Additional file 1 was reconstructed using BIONJ [26] implemented in Splitstree4 version 4.6 [28].

\section{Note added in proof}

The paper by Warthmann, Fitz and Weigel, submitted has now been accepted for publication: Warthmann, N., Fitz, J., and Weigel, D. (2007) MSQT for choosing SNP assays from multiple DNA alignments. Bioinformatics, accepted for publication.

\section{Authors' contributions}

CD constructed EST libraries, supervised the project, and wrote the paper, $\mathrm{MH}$ isolated and amplified genomic DNA, and identified the polymorphisms, MH and CL shared the sequencing projects, EMW did the phylogenetic reconstruction, MR and AS designed and maintained the MySQL databases, AS and CD assigned GO criteria, NW designed the primers, developed the MSQT and processed the sequences for SNP assay development, NT contributed to EST analysis and primer design, SRH supervised EMW, MR, and AS, provided bioinformatics tools and designed the MySQL database scheme, DW initiated the guppy project, co-supervised it and revised the manuscript.

All authors read and approved the final manuscript.

\section{Additional material}

\section{Additional file 1}

Phylogenetic reconstruction based on ten concatenated nuclear genes. This figure demonstrates application of expressed nuclear genes of the guppy for phylogenetic reconstruction.

Click here for file

[http://www.biomedcentral.com/content/supplementary/14712164-8-269-S1.pdf]

\section{Additional file 2}

Accession numbers of nuclear genes used for teleost phylogeny including guppy. Table of accession numbers of sequences used for phylogenetic reconstruction shown in additional file 1.

Click here for file

[http://www.biomedcentral.com/content/supplementary/14712164-8-269-S2.pdf]

\section{Acknowledgements}

We wish to thank Kay Nieselt for helpful suggestions; Heike Keller for expert technical assistance; Joffrey Fitz for help with MSQT design, Cheng Soon Ong and Gunnar Rätsch for help with intron site prediction; David Reznick, Felix Breden, Anne Magurran, and Axel Meyer for guppy strains; and Rainer Bohrer for regular updates of the BLAST database files used.

This work was funded by the Max Planck Society, of which DW is a director.

\section{References}

I. Winge Ö: The location of eighteen genes in Lebistes reticulatus . J Genetics 1927, 18:1-43.

2. Endler JA: Variation in the appearance of guppy color patterns to guppies and their predators under different visual conditions. Vision Res 1991, 31:587-608.

3. Endler JA: Multiple-trait coevolution and environmental gradients in guppies. Trends Ecol Evol 1995, 10:22-29.

4. Traut $\mathrm{W}$, Winking $\mathrm{H}$ : Meiotic chromosomes and stages of sex chromosome evolution in fish: zebrafish, platyfish and guppy. Chromosome Res 2001, 9:659-672.

5. Winge Ö, Ditlevsen E: Colour inheritance and sex determination in Lebistes. Heredity 1947, I:65-83.

6. Khoo G, Lim MH, Suresh H, Gan DK, Lim KF, Chen F, Chan WK, Lim TM, Phang VP: Genetic linkage maps of the guppy (Poecilia 
reticulata): assignment of RAPD markers to multipoint linkage groups. Mar Biotechnol (NY) 2003, 5:279-293.

7. Watanabe T, Nakajima M, Yoshida M, Taniguchi N: Construction of six linkage groups in the guppy (Poecilia reticulata). Anim Genet 2004, 35:147-148

8. Watanabe T, Yoshida M, Nakajima M, Taniguchi N: Linkage mapping of AFLP and microsatellite DNA markers with the body color- and sex- determining loci in the guppy (Poecilia reticulata). Zoolog Sci 2005, 22:883-889.

9. Kazianis S, Nairn RS, Walter RB, Johnston DA, Kumar J, Trono D, et al.: The genetic map of Xiphophorus fish represented by 24 multipoint linkage groups. Zebrafish 2004, I:287-304.

10. Brummell M, Kazianis S, Davidson WS, Breden F: Conservation of Synteny Between Guppy and Xiphophorus Genomes. Zebrafish 2006, 3:347-358.

11. Shimizu N, Sasaki T, Asakawa S, Shimizu A, Ishikawa SK, Imai S, Murayama $\mathrm{Y}$, Himmelbauer $\mathrm{H}$, Mitani $\mathrm{H}$, Furutani-Seiki M, et al:: Comparative genomics of medaka and fugu. Comparative Biochemistry and Physiology, Part D 2006, I:6-12.

12. Magurran AE: Evolutionary Ecology: The Trinidadian Guppy. Oxford University Press, Oxford; 2005.

13. Altschul SF, Gish W, Miller W, Myers EW, Lipman DJ: Basic local alignment search tool. Molecular Biology and Evolution 1990, 2I5:403.

14. MySQL [http://www.mysql.org]

15. Dzwillo M: Genetische Untersuchungen an domestizierten Stämmen von Lebistes reticulatus (Peters). Mitteilungen des Hamburgischen Zool Museum Inst 1959, 57:575-584

16. Ashburner M, Ball CA, Blake JA, Botstein D, Butler H, Cherry JM, Davis AP, Dolinski K, Dwight SS, Eppig JT, et al:: Gene ontology: tool for the unification of biology. The Gene Ontology Consortium. Nat Genet 2000, 25:25-29.

17. Paschall JE, Oleksiak MF, VanWye JD, Roach JL, Whitehead JA, Wyckoff G], Kolell KJ, Crawford DL: FunnyBase: a systems level functional annotation of Fundulus ESTs for the analysis of gene expression. BMC Genomics 2004, 5:96-108.

18. Pearson WR, Lipman DJ: Improved tools for biological sequence comparison. Proc Natl Acad Sci USA 1988, 85:2444-2448.

19. Mazumder B, Seshadri V, Fox PL: Translational control by the 3'UTR: the ends specify the means. Trends Biochem Sci 2003 , 28:91-98.

20. Jurinke C, van den Boom D, Cantor CR, Koster H: Automated genotyping using the DNA MassArray technology. Methods Mol Biol 200I, I70: 103-II6.

21. Staden R, Beal KF, Bonfield JK: The Staden package, 1998. Methods Mol Biol 2000, I 32: I I5-130.

22. Accelrys GCG I I.0 GenHelp Online Documentation [http:// www.accelrys.com/support/bio/genhelp/]

23. Becher SA, Russell ST, Magurran AE: Isolation and characterization of polymorphic microsatellites in the Trinidadian guppy (Poecilia reticulata). Molecular Ecology Notes 2002, 2:456-458.

24. Xu P, Wang S, Liu L, Peatman E, Somridhivej B, Thimmapuram J, Gong G, Liu Z: Channel catfish BAC-end sequences for marker development and assessment of syntenic conservation with other fish species. Animal Genetics 2006, 37:32I-326.

25. Breden F, Ptacek MB, Rashed M, Taphorn D, Figueiredo CA: Molec ular phylogeny of the Live-Bearing Fish Genus Poecilia (Cyprinodontiformes: Poecilidae). Molecular Phylogenetics and Evolution 1999, 12:95-104.

26. Hoffmann M, Tripathi N, Henz SR, Lindholm AK, Weigel D, Breden $\mathrm{F}$, Dreyer C: Opsin gene duplication and diversification in the guppy, a model for sexual selection. Proc Biol Sci 2007, 274:33-42.

27. Gascuel O: BIONJ: an improved version of the NJ algorithm based on a simple model of sequence data. Mol Biol Evol I997, 14:685-695.

28. Huson DH, Bryant D: Application of phylogenetic networks in evolutionary studies. Mol Biol Evol 2006, 23:254-267.

29. Guindon S, Gascuel O: Efficient biased estimation of evolutionary distances when substitution rates vary across sites. Mol Biol Evol 2002, 19:534-543.

30. Rosen DE, Bailey RM: The poeciliid fishes (Cyprinodontiformes), their structure, zoogeography and stystematics. Bull Am Mus Nat Hist 1963, 1 26: I- 176.

31. Parenti LR, Rauchenberger M: Systematic overview of the Poeciliines. In Ecology and evolution of livebearing fishes (Poecilidae) Edited by: Meffe GK, Snelson FF. Englewood Cliffs, New Jersey: Prentice Hall; 1989:3-12.

32. Volff JN, Korting C, Meyer A, Schartl M: Evolution and discontinuous distribution of Rex3 retrotransposons in fish. Mol Biol Evol 200I, | 8:427-43I.

33. Hrbek T, Seckinger J, Meyer A: A phylogenetic and biogeographic perspective on the evolution of poeciliid fishes. Mol Phylogenet Evol 2007, 43:986-998

34. Fajen A, Breden F: Mitochondrial DNA sequence variation among natural populations of the Trinidad Guppy. Evolution 1992, 46: | 457- I 465.

35. Alexander HJ, Breden F: Sexual isolation and extreme morphological divergence in the Cumana guppy: a possible case of incipient speciation. J Evol Biol 2004, 17: 1238-। 254.

36. Ewing B, Hillier L, Wend M, P G: Basecalling of automated sequencer traces using phred. I. Accuracy assessment. Genome Research 1998, 8:175-185.

37. Guppy Databases [http://guppy.weigelworld.org]

38. Rozen S, Skaletsky HJ: Primer3 on the WWW for general users and for biologist programmers. In Bioinformatics Methods and Protocols: Methods in Molecular Biology Edited by: Krawetz S, Misener S, Totowa, NJ. Humana Press; 2000:365-386.

39. EMBOSS [http://emboss.sourceforge.net/apps]

40. Rice P, Longden I, Bleasby A: EMBOSS: the European Molecular Biology Open Software Suite. Trends Genet 2000, 16:276-277.

4l. Edgar RC: MUSCLE: multiple sequence alignment with high accuracy and high throughput. Nucleic Acids Res 2004, 32: $1792-1797$.

Publish with Bio Med Central and every scientist can read your work free of charge

"BioMed Central will be the most significant development for disseminating the results of biomedical research in our lifetime. "

Sir Paul Nurse, Cancer Research UK

Your research papers will be:

- available free of charge to the entire biomedical community

- peer reviewed and published immediately upon acceptance

- cited in PubMed and archived on PubMed Central

- yours - you keep the copyright 